\title{
Geographic origin differentiation of Philippine civet coffee using an electronic nose
}

\author{
Emelda Ongo ${ }^{1,2}$, Matteo Falasconi ${ }^{3}$, Fortunato Sevilla III ${ }^{2 *}$, Giuseppe Montevecchi ${ }^{4}$, \\ Veronica Sberveglieri ${ }^{5}$, Isabella Concina ${ }^{3}$, E Giorgio Sberveglieri ${ }^{3}$ ${ }^{2}$ Graduate School, University of Santo Tomas, 1015 Manila, Philippines; ${ }^{3}$ CNR-IDASC SENSOR \& Brescia University, Via Valotti 9-, 25133 Brescia, Italy; ${ }^{4}$ Centro di Ricerca Interdipartimentale per il Miglioramento e la Valorizzazione delle Risorse Biologiche Agro-Alimentari BIOGEST-SITEIA, Università degli Studi di Modena e Reggio Emilia, Piazzale Europa 1 (Tecnopolo di Reggio Emilia), 42124 Reggio Emilia, Italy; ${ }^{5}$ Dipartimento di Scienze Agrarie e degli Alimenti, Universitá di Modena e Reggio Emilia, Via G. Amendola 2, 42122 Reggio Emilia, Italy \\ ${ }^{1}$ Industrial Technology Development Institute, DOST, Bicutan, Taguig, 1631 Metro Manila, Philippines;
}

\begin{abstract}
An increasing interest in geographical indication of origin has emerged to achieve legal protection of specialty coffee in international market. Civet coffee which is considered as the most expensive and best specialty coffee in the world, is one of the important indigenous export products of the Philippines. Thus, geographical origin differentiation of Philippine civet coffee and their control coffee beans (not eaten by civet) using electronic nose (E-nose) was performed. The E-nose instrument was based on six semiconductor metal oxide (SMO) sensor array. Results showed that the sensors exhibited different responses towards civet coffees and non-civet (control) coffees of different provenance. Principal component analysis (PCA) and Heirarchical cluster analysis (HCA) demonstrated a clearly separated civet coffees from their control beans. The cluster separation among civet coffee samples indicated that geographic origins dictate the aroma and flavor variations in coffee. This remarkable performance of E-nose provides proof that it is an excellent tool for authentication of the provenance of civet coffee and non-civet coffee samples.
\end{abstract}

Keywords: civet coffee, electronic nose, geographic origin, Principal Component Analysis, Hierarchical Cluster Analysis

\section{INTRODUCTION}

Civet coffee ranks as the top most expensive specialty coffee in the world due to its unique taste and aroma [1]. Its limited annual production and unusual process also dictate its

*To whom correspondence should be addressed fortunato.sevilla@ust.edu.ph / fortunatosevilla@yahoo.com high price in the international market. Civet coffee is made from the beans of coffee cherries, which have been eaten by the Asian palm civet (Paradoxurus hermaphroditus) and passed through its digestive tract. Civets naturally select and consume the ripest and sweetest coffee cherries, and excrete the undigested inner beans. The passage of the beans through the digestive tract of civet adds flavor to the coffee 
by breaking down the proteins that gives coffee its bitter taste [2].

Civet coffee is produced in only few countries including the Philippines. It has been recognized as one of the important indigenous export products of the country. Philippine civet coffee is derived mainly from the beans of Arabica and Robusta coffee trees found in the forests where the civet cat thrives, particularly those as in the mountains of the Cordillera region, Batangas, Davao, and Cotabato.

A growing interest in geographical indication of origin has emerged in the recent years in the specialty coffee market. Single-origin coffee has been recognized to exhibit distinct taste profiles that are determined by the unique microclimate and soil conditions where the coffee was grown [3]. The country and the region of origin have been shown to determine the prices paid by importers and roasters [4].

A need has been realized for reliable methods for the discrimination and authentication of geographic origin of coffee. Analytical methods based on gas chromatography-mass spectrometry (GC-MS) [5, 6], inductively coupled plasma atomic emission spectroscopy (ICP-AES), inductively coupled plasma mass spectroscopy (ICP-MS) [7-9], and isotope ratio mass spectrometry (IRMS) [10] have provided unique chemical signatures which are useful for the differentiation of coffee from different geographical origins. These methods are highly developed and used by legal authorities. However, they do not measure properties related to the perceived quality of coffee. A coffee origin signature in its volatile profile would have a direct link to the sensory attributes related to aroma which is significant for the acceptance of coffee.

This paper describes the differentiation of civet coffee from different geographical regions of the Philippines using an electronic nose. It also reports the capability of the e-nose to discriminate civet coffee and the coffee from which it was derived. The electronic nose instrument was based on a thin film semiconductor metal oxide (SMO) sensor array. The thin film SMO sensors offer several advantages such as good sensitivity towards a large spectrum of analytes, high stability, good reproducibility, and easy scaling up to industrial level [11]. The electronic nose has been previously employed for coffee quality assessment [12-13], classification and discrimination of different types, brands and blends of coffee [14-17]. To our knowledge, no report has yet been presented on the application of the electronic nose for geographic origin discrimination.

\section{EXPERIMENTAL}

Coffee samples. The roasted civet coffee and their corresponding control beans (not eaten by civet) were taken from different places in the Philippines. Arabica and Robusta are the civet varieties used in the experiment. The Robusta civet and control coffee beans were taken from the northern part of the Philippines (Kalinga Province and Asipulo, Ifugao

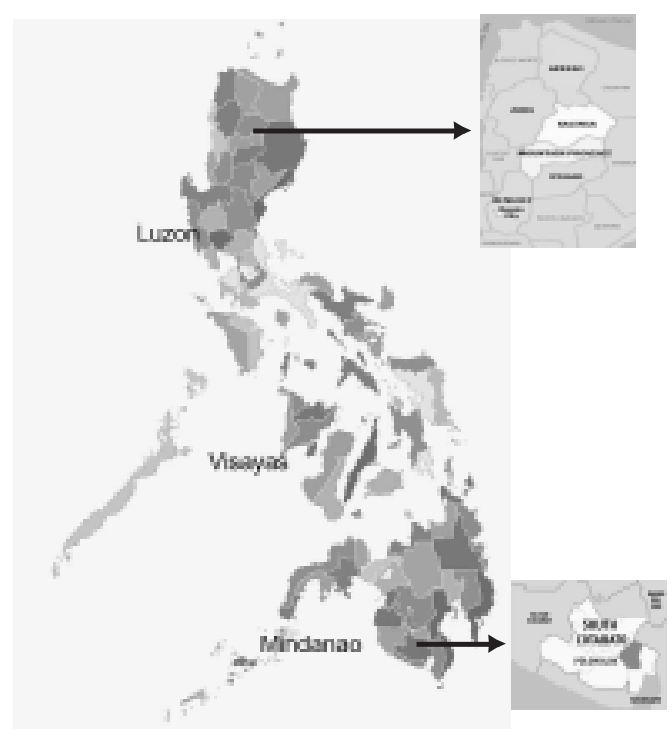

Figure 1. Map of the Philippines, showing the site of the geographic origin of the coffee samples. 
Province) while Arabica coffees were procured from the southern part (Matutum, South Cotabato) and the northern part (Cordillera, Mountain Province) of the country. A map of the Philippines indicating the sites of the geographic origin of the coffee samples is shown in Fig. 1.

Electronic nose measurement. The electronic nose used in the study was the Electronic Olfactory System, EOS $_{835}$ (SACMI IMOLA scarl, Italy). It is composed of a pneumatic assembly for dynamic sampling, a thermally controlled sensor chamber housing an array of gas sensors, and an electronic system for controlling the sensor heating temperature and measuring the sensor response (Fig. 2). The sensor array consisted of six metal oxide semiconductor thin-film sensors whose resistance is affected by the presence of vapors (Table 1). The instrument is interfaced to a computer with a Nose Pattern Editor software (Sacmi Imola scarl, Italy) for data acquisition and statistical data evaluation.

About $3 \mathrm{~g}$ of roasted coffee beans were placed in a $20 \mathrm{~mL}$ airtight sealed glass vial. Headspace generation was held at $40^{\circ} \mathrm{C}$ for 10 min with

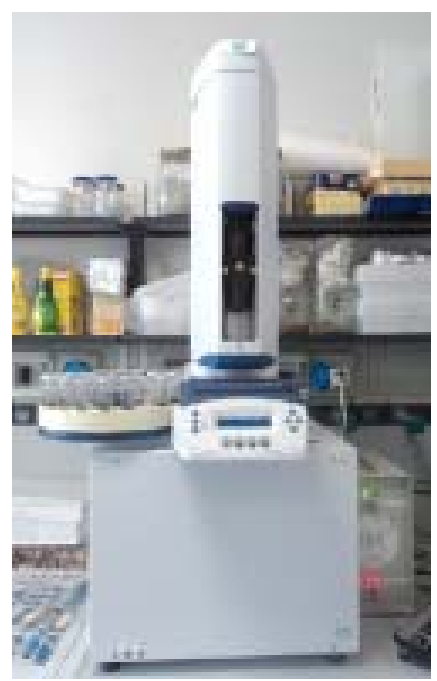

Figure 2. Electronic Olfactory System 835 (E-nose)
Table 1. Sensor array configuration

\begin{tabular}{c|c|c|c}
\hline No. & $\begin{array}{c}\text { Sensing } \\
\text { Layer }\end{array}$ & Catalyst & $\begin{array}{c}\text { Operating T } \\
\left({ }^{\circ} \mathbf{C}\right)\end{array}$ \\
\hline \hline 1 & $\mathrm{SnO}_{2}-\mathrm{RGTO}^{\mathrm{a}}$ & $\mathrm{Au}$ & $400-500$ \\
\hline 2 & $\mathrm{SnO}_{2}-\mathrm{RGTO}^{\mathrm{a}}$ & $\mathrm{Ag}$ & $400-500$ \\
\hline 3 & $\mathrm{SnO}_{2}-\mathrm{RGTO}^{\mathrm{a}}$ & $\mathrm{Mo}$ & $400-500$ \\
\hline 4 & $\mathrm{WO}_{3}{ }^{\mathrm{b}}$ & None & $250-350$ \\
\hline 5 & $\mathrm{SnO}_{2}-\mathrm{RGTO}^{\mathrm{a}}$ & None & $350-500$ \\
\hline 6 & $\mathrm{SnO}_{2}-\mathrm{In}_{2} \mathrm{O}^{\mathrm{c}}$ & None & $400-500$ \\
\hline \multicolumn{4}{|c}{${ }^{\mathrm{T}} \mathrm{Tin} \mathrm{Oxide-Rheotaxial} \mathrm{Growth} \mathrm{and} \mathrm{Thermal}$} \\
Oxidation technique; ${ }^{\mathrm{b}}$ Tungsten Oxide; ${ }^{\mathrm{c}}$ Tin- \\
Indium Oxide
\end{tabular}

1 min shaking. Then, headspace volume of $2 \mathrm{~mL}$ was extracted and injected into the carrier line. The injection temperature was $50^{\circ} \mathrm{C}$ with injection speed of $4 \mathrm{~mL} / \mathrm{min}$.

Measurements were performed by static headspace using an automated sampling unit provided by a 40 loading position carousel. The measurement cycle consisted of the run for each of the 36 different coffee samples and four calibration samples. The calibration sample was standard solvent ( $n$-butanol, SigmaAldrich) and measurements on it were evenly positioned and alternately analyzed with real coffee samples in order to evaluate and correct possible measurement drifts. The civet coffee beans were analyzed together with their control coffee beans.

Statistical analysis. Principal component analysis (PCA) and cluster analysis were performed using Statistica version 8.0 software (Stat 180 Soft Inc., Tulsa, USA) and Microsoft Excel $^{\mathrm{TM}}$ statistiXL, Version 1.6 (statistiXL, Broadway - Nedlands, Western Australia).

\section{RESUlTS AND DISCUSSION}

E-nose response to coffee samples. The MOS sensors in the E-nose responded immediately at different extents to civet coffee samples. Most of the sensors attained a steady-state response within $300 \mathrm{~s}$. The sensor responses exhibited good repeatability and reversibility, 


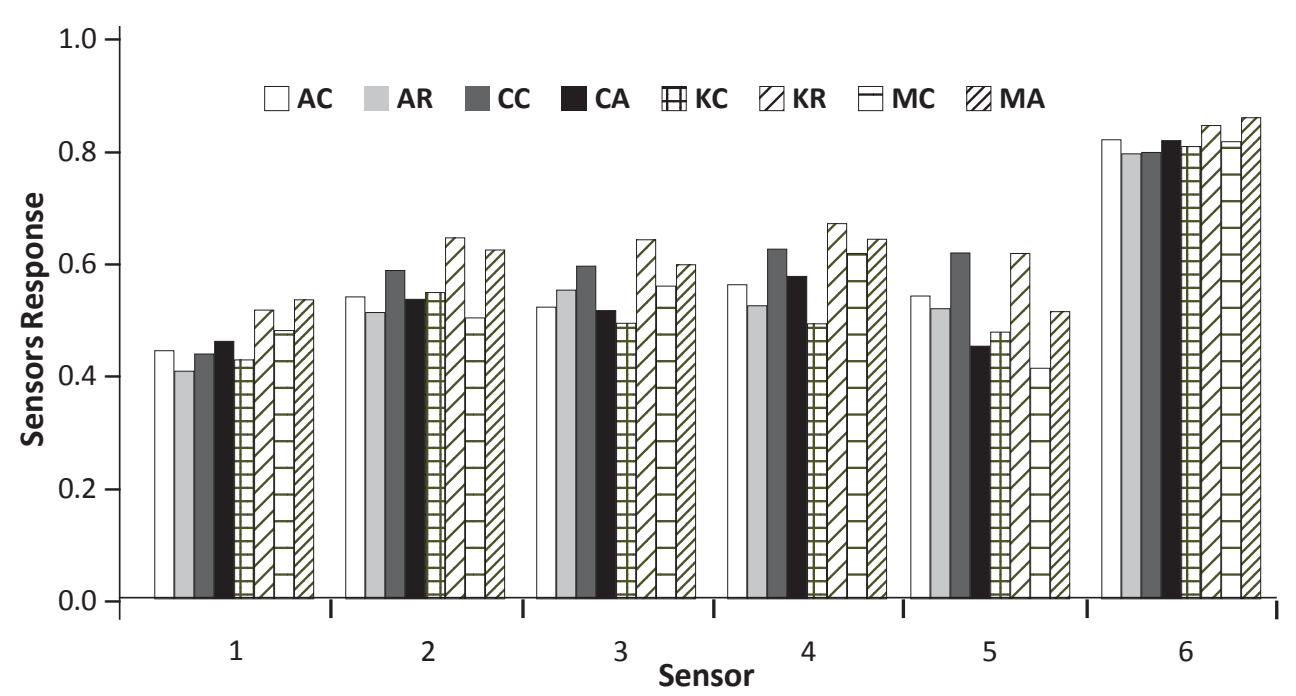

Figure 3. Response magnitude of different sensors to coffee samples (mean, $n=8$ ). (AC-Asipulo Civet, AR-Asipulo Robusta, CC-Cordillera Civet, CA-Cordillera Arabica, KC-Kalinga Civet, KR-Kalinga Robusta, MC-Matutum Civet, MA-Matutum Arabica)

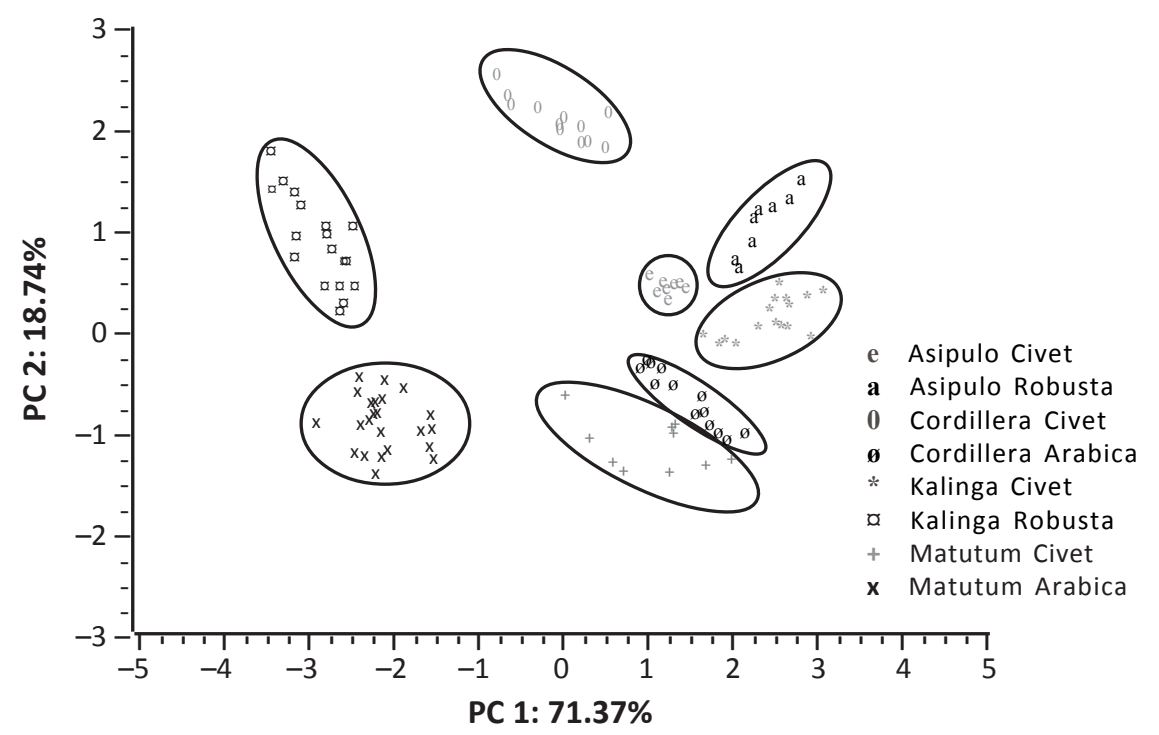

Figure 4. E-nose PCA score plot of different civet coffee and non-civet coffee samples.

the relative standard deviation (RSD) obtained for the sensors response ranging from 0.14 to 6.93. Also, the sensor array displayed a very good reproducibility in its response toward the volatile compounds in the headspace of the coffee samples. Figure 3 presents the response of the component sensors to the civet coffee and non-civet coffee samples of different geographic origin.

Coffee discrimination and classification. The variation of the sensor responses with the geographic origin of the civet coffee and non- 


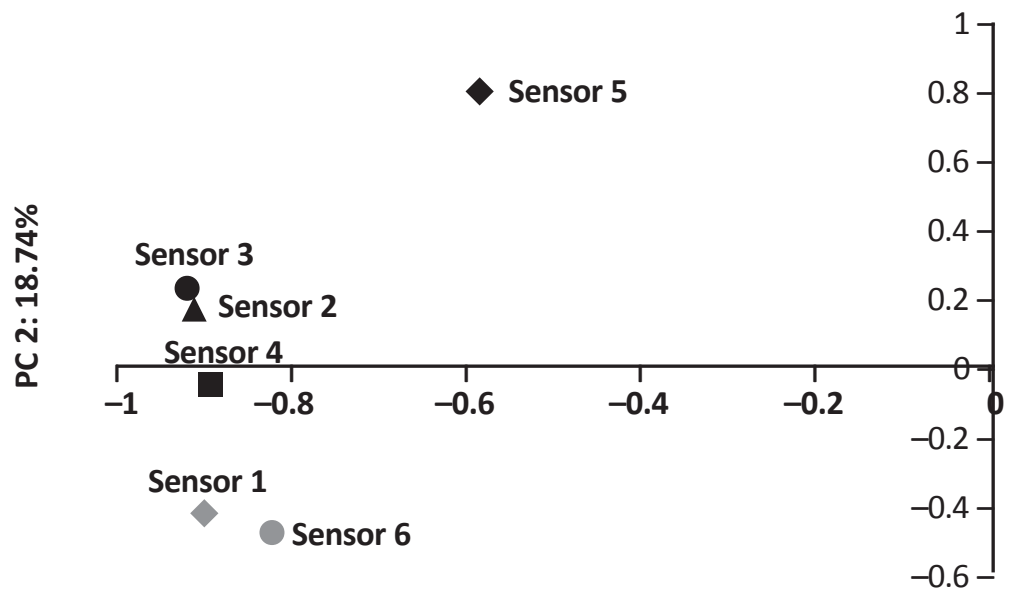

PC 1: 71.37\%

Figure 5. PC loading analysis for civet and control coffee beans.

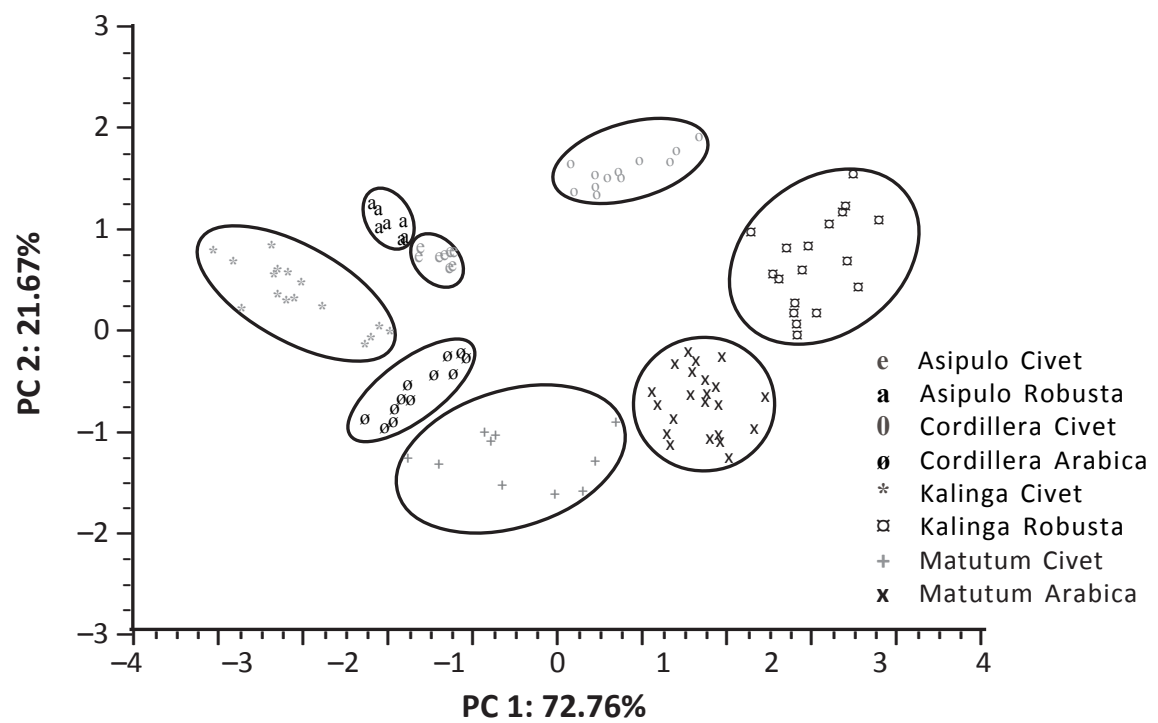

Figure 6. PCA plot of 4 sensors for civet and control coffees.

civet coffee samples could not be easily discerned in Fig. 3. A multivariate analysis has to be carried out in order to differentiate and discriminate coffee samples of different provenance.
A principal component analysis (PCA) was performed to further present the experimental results visually and highlight the variations or similarities in the data. Chemometric techniques were carried out to reduce the dimensionality of the data set to two principal components. A 


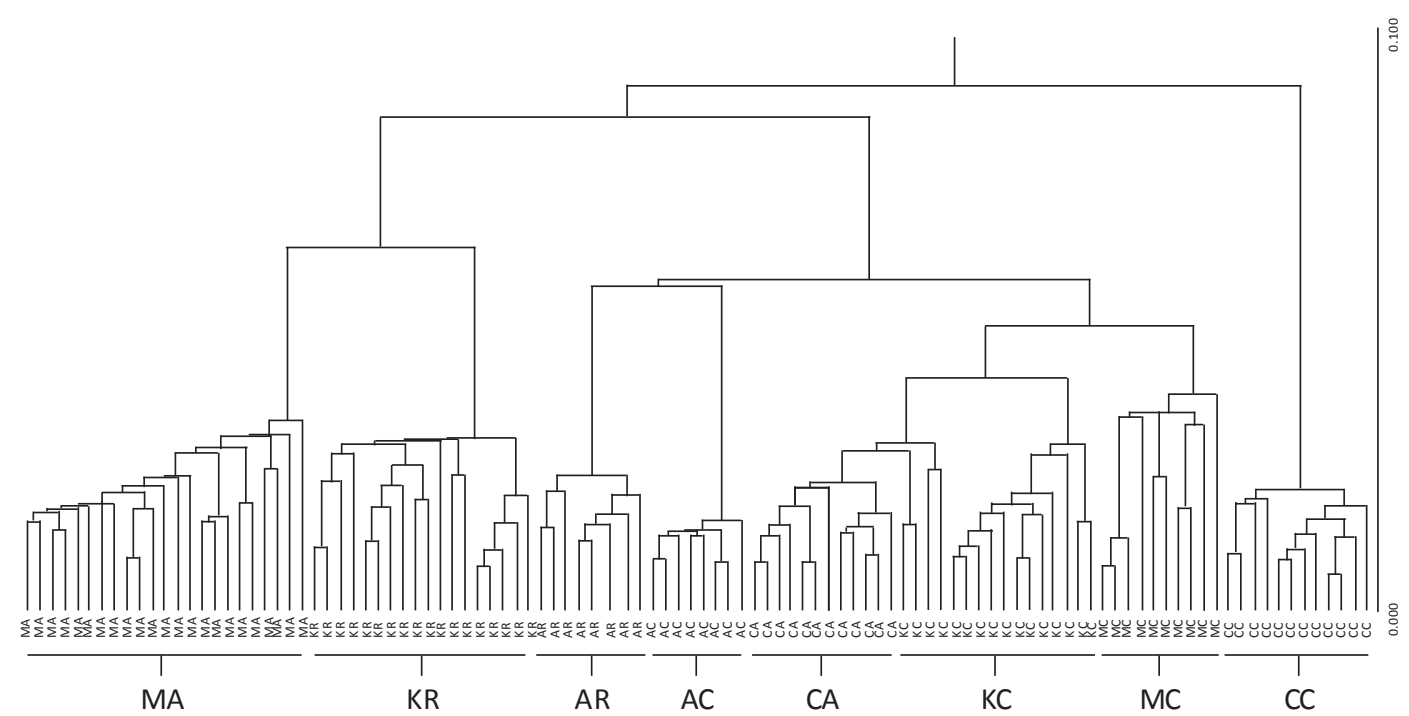

Figure 7. Cluster Analysis (Dendrogram) of civet and control coffee beans. (AC-Asipulo Civet, AR-Asipulo Robusta, CCCordillera Civet, CA-Cordillera Arabica, KC-Kalinga Civet, KR-Kalinga Robusta, MC-Matutum Civet, MA-Matutum Arabica)

comprehensive view of the PCA score plot of the E-nose data obtained from civet coffee and non-civet coffee samples is illustrated in Fig. 4.

The 2D plot in Fig. 4 shows a strong discrimination of the coffee samples according to their geographic origins, both for the civet coffee and non-civet coffee. The first principal component (PC1) accounts for $71.37 \%$ of the total variance of $90.11 \%$. The second principal component (PC2) explains $18.74 \%$ of the variation.

The distances among the samples reflect the level of distinction. The first component PC1 effectively differentiates the clusters of the Arabica non-civet coffee samples from Cordillera and Matutum, and the clusters of the Robusta non-civet coffee samples from Kalinga and Asipulo. However, this component poorly differentiates the civet coffee samples from different regions. The second principal component PC2 strongly discriminates the Arabica civet coffee from Matutum and from Cordillera, and separates to a small extent the
Robusta civet coffee samples from Kalinga and Asipulo. This component poorly differentiates the non-civet coffee from different origins. The grouping indicates that the headspace vapour, and therefore the aroma, of each coffee is region-specific. The distinct data structure of the individual civet coffee shows that the passage of the beans through the digestive tract of civet affects the aroma attributes of coffee beans.

The loading analysis of the sensor responses for the coffee samples from different origins using the first two PCs is presented in Fig. 5. The weight of the loading for a particular PC directly reflects the contribution of the sensors and explains the discrimination among samples. The sensor with an absolute PC loading value greater than some acceptable values has a high contribution to the total response variation of the sensors and is called a discriminating sensor; whereas, the sensor with very low loading value is described as an undesirable sensor. It is shown 
that sensors 1,2, 3, 4, and 6 have a great influence in the discrimination among samples at PC1. These sensors accounted for most of the variance at $\mathrm{PC} 1$ plane $(71.37 \%)$. While sensor 5 contributed a fairly high variance at PC2 indicating that it is mainly responsible for the discrimination among samples at PC2 plane. Those sensors that gave a very close PCs loading values can be grouped as one since they exhibited equal discrimination impact (redundancy of variables) like in the case of sensors 2, 3, and 4 as well as sensors 1 and 6 . The PC loading analysis explicitly explained that even four sensors are enough to discriminate one sample from the others. The clustering using four sensors shown in Fig. 6 improves the separation in two PCs (PC1 and $\mathrm{PC} 2$ ) from $18.74 \%$ to $21.67 \%$ at $\mathrm{PC} 1$ and $71.37 \%$ to $72.76 \%$ at $\mathrm{PC} 2$.

Heirarchical cluster analysis was applied to the set of sensor responses to determine the similarity of various coffee groups. The dendrogram graph (Fig. 7) presents the level of similarity among samples as depicted by the distance at which clusters were joined. Based on this graph, there is great discrimination between the Arabica civet coffee from Matutum (MC) and Cordillera (CC), and between the Robusta civet coffee from Kalinga (KC) and Asipulo (AC). Likewise, the separation is very distinct for non-civet coffee from different origins and different varieties.

\section{CONCLUSION}

The geographic origins of the civet coffee and non-civet coffee samples from different geographic origins could be differentiated through responses of the component sensors in the electronic nose. The sensor responses also discriminate civet coffee and non-civet coffee. The variation of the sensor responses is associated with the composition of the vapor in the headspace of the coffee bean samples. The results show that the electronic nose is an excellent tool for the authentication of the provenance of civet coffee and non-civet coffee samples.

\section{ACKNOWLEDGMENTS}

This research work was funded by the Philippine Council for Industry, Energy and Emerging Technology Research and Development (PCIEERD), Department of Science and Technology (DOST), Philippines, the University of Modena and Reggio Emilia and the University of Brescia, Italy. One of the authors (E.O) gratefully acknowledges the sandwich thesis grant provided to her by DOST-PCIEERD.

\section{REFERENCES}

[1] Wild T. Civet cat coffee: can world's most expensive brew be made sustainably? The Guardian. (United Kingdom, 19 September 2014). http://www.theguardian.com/sustainableb u s i n e s s/2014/s e p/19/ civet-cat-coffee-worlds-most-expensive-brewmade-sustainably-kopi-luwak)

[2] Marcone MF. Composition and properties of Indonesian palm civet coffee (Kopi Luwak) and Ethiopian civet coffee. Food Res. Int. 2004; 37:901912.

[3] Teuber R. Geographical indication of origin as a tool for product differentiation: The case of coffee. J. Int. Food Agribus. Mark. 2010; 22:277-298.

[4] Wilson BR, Conley JF, Harris TM, \& Lafone F. New terrains of taste: Spatial analysis of price premiums for single origin coffees in Central America. Appl. Geogr. 2012; 35:499-507.

[5] Costa Freitas AM, Parreira C, \& Vilas-Boas L. The Use of an Electronic Aroma-sensing Device to Assess Coffee Differentiation-Comparison with SPME Gas Chromatography-Mass Spectrometry Aroma Patterns. J. Food Comp. Anal. 2001; 14:513-522.

[6] Risticevic S, Carasek E, \& Pawliszyn J. Headspace solid-phase microextraction-gas chromatographictime-of-flight mass spectrometric methodology for geographical origin verification of coffee. Anal. Chim. Acta 2008; 617:72-84.

[7] Anderson KA \& Smith BW. Chemical profiling to differentiate geographic growing origins of coffee. J. Agric. Food Chem. 2002; 50:20682075. 
[8] Valentin JL \& Watling RJ. Provenance establishment of coffee using solution ICP-MS and ICP-AES. Food Chem. 2013; 141:98-104.

[9] Liu HC, You CF, Chen CY, Liu YC, \& Chung MT. Geographic determination of coffee beans using multi-element analysis and isotope ratios of boron and strontium. Food Chem. 2014; 142:439-445.

[10] Rodrigues Cl, Maia R, Miranda M, Riberinho M, Nogueira JMF, \& Maaguas C. Stable isotope analysis for green coffee bean: A possible method for geographic origin discrimination. J. Food Comp. Anal. 2009; 22:463-471.

[11] Falasconi M, Pardo M, Sberveglieri G, Nardini F, Della T, \& Bresciani A. The novel EOS835 electronic nose sniffs out the Italian espresso coffee quality. In: Proceedings of IEEE Sensors 2003, Toronto, Canada, 26-29.

[12] Rodríguez J, Durán C, \& Reyes A. Electronic nose for quality control of Colombian coffee through the detection of defects in "Cup Tests". Sensors 2010; 10:36-42.
[13] Shilbayeh NF \& Iskandarani MZ. Quality control of coffee using an electronic nose system. Am. J. Appl. Sci. 2004; 1:129-135.

[14] Ulmer H, Mitrovics J, Noetzel G, Wiemar U, \& Gopel W. Odours and flavours identified with hybrid modular sensor systems. Sens. Actuat. B. Chem. 1992; 43:24-33.

[15] Pardo M \& Sberveglieri G. Coffee analysis with an electronic nose. IEEE Trans. Instrum. Meas. 2002; 51:1334-1339.

[16] Wang X, Ye M, \& Duanmu CJ. Classification of data from electronic nose using relevance vector machines. Sens. Actuat. B. Chem. 2009; 140:143148.

[17] Pardo M, Niederjaufner G, Benussi G, Comini E, Faglia G, Sberveglieri G, Holmberg M, \& Lundstrom I. Data preprocessing enhances the classification of different brands of Espresso coffee with an electronic nose. Sens. Actuat. B. Chem. 2000; 69:397-403. 